MSC 47D06, 49J15, 93C25

DOI: $10.14529 / \mathrm{mmp} 140314$

\title{
OPTIMAL CONTROL OF SOLUTIONS TO THE MULTIPOINT INITIAL-FINAL PROBLEM FOR NONSTATIONARY RELATIVELY BOUNDED EQUATIONS OF SOBOLEV TYPE
}

\author{
M.A. Sagadeeva, South Ural State University, Chelyabinsk, Russian Federation, \\ sam79@74.ru,
}

A.D. Badoyan, South Ural State University, Chelyabinsk, Russian Federation, badoyanani@mail.ru

We study the problem of optimal control of solutions to an operator-differential equation, which is not solved with respect to the time derivative, together with a multipoint initial-final condition. In this case, one of the operators in the equation is multiplied by a scalar function of time. By the properties of the operators involved, the stationary equation has analytical resolving group. We construct a solution to the multipoint initialfinal problem for the nonstationary equation. We show that a unique optimal control of solutions to this problem exists.

Apart from the introduction and bibliography, the article consists of three sections. The first section provides the essentials of the theory of relatively $p$-bounded operators. In the second section we construct a strong solution to the multipoint initial-final problem for nonstationary Sobolev-type equations. The third section contains our proof that there exists a unique optimal control of solutions to the multipoint initial-final problem.

Keywords: optimal control; multipoint initial-final problem; Sobolev-type equations; relatively bounded operator.

\section{Introduction}

Suppose that $\mathfrak{X}, \mathfrak{Y}$, and $\mathfrak{U}$ are Hilbert spaces, and then take bounded linear operators $L \in \mathcal{L}(\mathfrak{X} ; \mathfrak{Y})$ and $B \in \mathcal{L}(\mathfrak{U} ; \mathfrak{Y})$, assuming that the kernel of $L$ is non-trivial. Take also a closed linear operator $M \in \mathcal{C l}(\mathfrak{X} ; \mathfrak{Y})$ whose domain is dense in $\mathfrak{X}$.

Consider the Sobolev-type equation [1-4]

$$
L \dot{x}(t)=a(t) M x(t)+f(t)+B u(t)
$$

with a control vector function $u:[0, T] \rightarrow \mathfrak{U}$, a vector function $f:[0, T] \rightarrow \mathfrak{Y}$ of exterior force, and a scalar function $a:[0, T] \rightarrow \mathbb{R}_{+}$, to be specified later, characterizing the change in time of the parameters of (1). The operators $L$ and $M$ generate the analytic resolving group for the homogeneous stationary equation (1), which means that $a(t) \equiv 1$.

We consider an optimal control problem for (1). Namely, we aim to find a pair $(\hat{x}, \hat{u}) \in$ $\mathfrak{X} \times \mathfrak{U}_{a d}$ with

$$
J(\hat{x}, \hat{u})=\inf _{(x, u) \in \mathfrak{X} \times \mathfrak{U}_{a d}} J(x, u) .
$$

Here $\mathfrak{U}_{a d}$ is a closed convex set of admissible controls in the Hilbert space $\mathfrak{U}$ of controls, all pairs $(x, u)$ satisfy the multipoint initial-final problem [5] for $(1)$, and $J(x, u)$ is a certain penalty functional in special form.

Previously the authors studied the optimal control problem for solutions to nonstationary Sobolev-type equations (1) with the Showalter-Sidorov condition [6, 7]. In this 
paper we study the optimal control of solutions to the multipoint initial-final problem [5], which is a generalized Showalter-Sidorov problem [8] for (1).

\section{Relatively Spectrally Bounded Operators}

Recall the standard notation of the theory of relatively $p$-bounded operators [3].

Starting with two Hilbert spaces $\mathfrak{X}$ and $\mathfrak{Y}$, take a bounded linear operator $L \in \mathcal{L}(\mathfrak{X} ; \mathfrak{Y})$ with non-trivial kernel and a closed linear operator $M \in \mathcal{C l}(\mathfrak{X} ; \mathfrak{Y})$ whose domain is dense in $\mathfrak{X}$. Consider the stationary equation

$$
L \dot{x}(t)=M x(t)+f(t),
$$

called a Sobolev-type equation [3].

Definition 1. The sets $\rho^{L}(M)=\left\{\mu \in \mathbb{C}:(\mu L-M)^{-1} \in \mathcal{L}(\mathfrak{Y} ; \mathfrak{X})\right\}$ and $\sigma^{L}(M)=$ $\mathbb{C} \backslash \rho^{L}(M)$ are called the $L$-resolvent set and the $L$-spectrum of $M$ respectively.

Definition 2. The operator-valued functions $(\mu L-M)^{-1}, R_{\mu}^{L}(M)=(\mu L-M)^{-1} L$, and $L_{\mu}^{L}(M)=L(\mu L-M)^{-1}$ are respectively called the resolvent, right resolvent, and left resolvent of $M$ with respect to $L$ (or briefly the $L$-resolvent, right L-resolvent, and left L-resolvent of $M$ ).

Lemma 1. Given $L \in \mathcal{L}(\mathfrak{X} ; \mathfrak{Y})$ and $M \in \mathcal{C} l(\mathfrak{X} ; \mathfrak{Y})$, the $L$-resolvent, right and left $L$ resolvents of $M$ are analytic on $\rho^{L}(M)$.

Definition 3. An operator $M$ is called spectrally bounded with respect to an operator $L$ (or briefly $(L, \sigma)$-bounded) whenever $\exists r_{0}>0 \quad \forall \mu \in \mathbb{C} \quad\left(|\mu|>r_{0}\right) \Rightarrow\left(\mu \in \rho^{L}(M)\right)$.

Put $\gamma=\left\{\mu \in \mathbb{C}:|\mu|=r>r_{0}\right\}$. The Riesz-type integrals

$$
P=\frac{1}{2 \pi i} \int_{\gamma} R_{\mu}^{L}(M) d \mu, \quad Q=\frac{1}{2 \pi i} \int_{\gamma} L_{\mu}^{L}(M) d \mu
$$

exist by Lemma 1 for every $(L, \sigma)$-bounded operator $M$. The operators $P \in \mathcal{L}(\mathfrak{X})$ and $Q \in \mathcal{L}(\mathfrak{Y})$ are projections [3]. Put $\mathfrak{X}^{0}=\operatorname{ker} P, \mathfrak{Y}^{0}=\operatorname{ker} Q ; \mathfrak{X}^{1}=\operatorname{im} P$, and $\mathfrak{Y}^{1}=\operatorname{im} Q$. Denote the restriction of $L(M)$ to $\mathfrak{X}^{k}$ by $L_{k}\left(M_{k}\right)$ for $k=0,1$.

Theorem 1. The following claims hold for every $(L, \sigma)$-bounded operator $M$ :

(i) the operators $L_{k}, M_{k}: \mathfrak{X}^{k} \rightarrow \mathfrak{Y}^{k}$ for $k=0,1$;

(ii) the operators $M_{0} \in \mathcal{L}\left(\mathfrak{X}^{0} ; \mathfrak{Y}^{0}\right)$ and $M_{1} \in \mathcal{C} l\left(\mathfrak{X}^{1} ; \mathfrak{Y}^{1}\right)$;

(iii) there exists operators $L_{1}^{-1} \in \mathcal{L}\left(\mathfrak{Y}^{1} ; \mathfrak{X}^{1}\right)$ and $M_{0}^{-1} \in \mathcal{L}\left(\mathfrak{Y}^{0} ; \mathfrak{X}^{0}\right)$;

(iv) there exist analytic resolving operator groups $\left\{X^{t} \in \mathcal{L}(\mathfrak{X}): t \in \mathbb{R}\right\}$ for the homogeneous equation (3) and $\left\{Y^{t} \in \mathcal{L}(\mathfrak{Y}): t \in \mathbb{R}\right\}$ for the equation $R_{\beta}^{L}(M) \dot{y}(t)=$ $M(\beta L-M)^{-1} y(t)$, where $\beta \in \rho^{L}(M)$, which are of the form

$$
X^{t}=e^{t L_{1}^{-1} M_{1}} P=\frac{1}{2 \pi i} \int_{\gamma} R_{\mu}^{L}(M) e^{\mu t} d \mu \quad Y^{t}=e^{t M_{1} L_{1}^{-1}} Q=\frac{1}{2 \pi i} \int_{\gamma} L_{\mu}^{L}(M) e^{\mu t} d \mu .
$$

Theorem 1 implies the existence of the operators $H=M_{0}^{-1} L_{0} \in \mathcal{L}\left(\mathfrak{X}^{0}\right)$ and $S=$ $L_{1}^{-1} M_{1} \in \mathcal{L}\left(\mathfrak{X}^{1}\right)$. 
Definition 4. An $(L, \sigma)$-bounded operator $M$ is called

(i) $(L, 0)$-bounded whenever the point $\infty$ is a removable singularity of the $L$-resolvent of $M$, that is, $H \equiv \mathbb{O}$;

(ii) $(L, p)$-bounded whenever the point $\infty$ is an order $p \in \mathbb{N}$ pole of the $L$-resolvent of $M$, that is, $H^{p} \neq \mathbb{O}$ and $H^{p+1} \equiv \mathbb{O}$;

(iii) $(L, \infty)$-bounded whenever the point $\infty$ is an essential singularity of the $L$-resolvent of $M$, that is, $H^{q} \neq \mathbb{O}$ for all $q \in \mathbb{N}$.

\section{Strong Solutions of the Multipoint Problem}

Take two Hilbert spaces $\mathfrak{X}$ and $\mathfrak{Y}$. For two operators $L \in \mathcal{L}(\mathfrak{X} ; \mathfrak{Y})$ and $M \in \mathcal{C} l(\mathfrak{X} ; \mathfrak{Y})$, where $M$ is $(L, p)$-bounded for $p \in\{0\} \cup \mathbb{N}$, introduce the condition

$$
\left.\begin{array}{c}
\sigma^{L}(M)=\bigcup_{j=0}^{n} \sigma_{j}^{L}(M), n \in \mathbb{N} \text {, and } \sigma_{j}^{L}(M) \neq \emptyset \text {, there is a closed loop } \gamma_{j} \subset \mathbb{C} \\
\text { and } \gamma_{j}=\partial D_{j}, \text { where } D_{j} \supset \sigma_{j}^{L}(M) \text {, such that } \overline{D_{j}} \cap \sigma_{0}^{L}(M)=\emptyset \\
\text { and } \overline{D_{k}} \cap \overline{D_{l}}=\emptyset \text { for all } j, k, l=\overline{1, n}, k \neq l .
\end{array}\right\}
$$

Define the operators $P_{j} \in \mathcal{L}(\mathfrak{X})$ and $Q_{j} \in \mathcal{L}(\mathfrak{Y})$ for $j=\overline{j, n}$ as

$$
P_{j}=\frac{1}{2 \pi i} \int_{\gamma_{j}} R_{\mu}^{L}(M) d \mu, \quad Q_{j}=\frac{1}{2 \pi i} \int_{\gamma_{j}} L_{\mu}^{L}(M) d \mu, \quad j=\overline{1, n}
$$

thanks to the relative spectral theorem [9], and moreover, the results of [9], and the operators $\quad P_{0}=P-\sum_{j=1}^{n} P_{j}, \quad Q_{0}=Q-\sum_{j=1}^{n} Q_{j}$.

Consider the multipoint initial-final problem

$$
P_{j}\left(x\left(\tau_{j}\right)-x_{j}\right)=0, \quad\left(\tau_{j}<\tau_{j+1}\right) \quad j=\overline{0, n}
$$

for (3). Applying to (3) the projections $\mathbb{I}-Q$ and $Q_{j}$ for $j=\overline{0, n}$ yields the equivalent system

$$
\begin{aligned}
& H \dot{x}^{0}=x^{0}+M_{0}^{-1} f^{0}, \\
& \dot{x}_{j}^{1}=S_{1 j} x_{j}^{1}+L_{1 j}^{-1} f_{j}^{1},
\end{aligned}
$$

where $H=M_{0}^{-1} L_{0} \in \mathcal{L}\left(\mathfrak{X}^{0}\right)$ is a degree $p \in\{0\} \cup \mathbb{N}$ nilpotent operator, the operator $S_{1 j}=L_{1 j}^{-1} M_{1 j} \in \mathcal{C l}\left(\mathfrak{X}_{j}^{1}\right)$ has the range $\sigma\left(S_{j}\right)=\sigma_{j}^{L}(M)$, while $f^{0}=(\mathbb{I}-Q) f, f_{j}^{1}=Q_{j} f$, $x^{0}=(\mathbb{I}-P) x$, and $x_{j}^{1}=P_{j} x$ for $j=\overline{0, n}$.

Put $\mathbb{N}_{0} \equiv\{0\} \cup \mathbb{N}$ and construct the space

$$
H^{p+1}(\mathfrak{Y})=\left\{\xi \in L_{2}(0, \tau ; \mathfrak{Y}): \xi^{(p+1)} \in L_{2}(0, T ; \mathfrak{Y}), p \in \mathbb{N}_{0}\right\}
$$

which is a Hilbert space with the inner product

$$
[\xi, \eta]=\sum_{q=0}^{p+1} \int_{0}^{\tau}\left\langle\xi^{(q)}, \eta^{(q)}\right\rangle_{\mathfrak{Y}} d t
$$

Definition 5. A vector-valued function $x \in H^{1}(\mathfrak{X})$ is called a strong solution to the multipoint initial-final problem (3), (5) whenever it satisfies (3) and the terms of $P_{j}\left(x\left(\tau_{j}\right)-x_{j}\right)=0 \quad$ for $j=\overline{0, n}$ almost everywhere. 
Lemma 2. If an operator $M$ is $(L, p)$-bounded, with $p \in \mathbb{N}_{0}$, then for every vector function $f^{0} \in H^{p+1}\left(\mathfrak{Y}^{0}\right)$ there exists a unique solution $x^{0} \in H^{1}\left(\mathfrak{X}^{0}\right)$ to $(6)$ :

$$
x^{0}(t)=-\sum_{q=0}^{p} H^{q} M_{0}^{-1} \frac{d^{q}}{d t^{q}} f^{0}(t) .
$$

Lemma 3. Under the assumptions of Lemma 2, if condition (4) is fulfilled then for every vector $x_{j} \in \mathfrak{X}$ and every vector function $f_{j}^{1} \in H\left(\mathfrak{Y}_{j}^{1}\right)$ there exists a unique solution $x_{j}^{1} \in$ $H^{1}\left(\mathfrak{X}_{j}^{1}\right)$ to the problem $P_{j}\left(x\left(\tau_{j}\right)-x_{j}\right)=0$ for $(7): x_{j}^{1}(t)=X_{j}^{t-\tau_{j}} x_{\tau_{j}}-\int_{t}^{\tau_{j}} X_{j}^{t-s} L_{1 j}^{-1} f_{j}^{1}(s) d s$.

Theorem 2. Given vectors $x_{j} \in \mathfrak{X}$ for $j=\overline{0, n}$ and a vector function $f:[0, \tau] \rightarrow \mathfrak{Y}$ satisfying the assumptions of Lemmas 2 and 3 , there exists a unique solution $x \in H^{1}(\mathfrak{X})$ :

$$
x(t)=-\sum_{q=0}^{p} H^{q} M_{0}^{-1} \frac{d^{q}}{d t^{q}} f^{0}(t)+\sum_{j=0}^{n}\left(X_{j}^{t-\tau_{j}} x_{\tau_{j}}-\int_{t}^{\tau_{j}} X_{j}^{t-s} L_{1 j}^{-1} f_{j}^{1}(s) d s\right) .
$$

\section{Optimal Control of the Multipoint Problem}

For a Hilbert space $\mathfrak{X}$ consider the equation

$$
L \dot{x}(t)=a(t) M x(t)+f(t)+B u(t)
$$

with operators $L \in \mathcal{L}(\mathfrak{X} ; \mathfrak{Y}), M \in \mathcal{C} l(\mathfrak{X} ; \mathfrak{Y})$, and $B \in \mathcal{L}(\mathfrak{U} ; \mathfrak{Y})$, a scalar function $a$ : $[0, \tau) \rightarrow \mathbb{R}_{+}$, as well as vector functions $u:[0, \tau) \rightarrow \mathfrak{U}$ and $f:[0, \tau) \rightarrow \mathfrak{Y}$ to be specified later.

Take a Hilbert space $\mathfrak{Z}$ and an operator $C \in \mathcal{L}(\mathfrak{X} ; \mathfrak{Z})$. Consider the penalty functional

$$
J(u)=\sum_{q=0}^{1} \int_{0}^{\tau}\left\|z^{(q)}-z_{d}^{(q)}\right\|_{\mathfrak{Z}}^{2} d t+\sum_{q=0}^{k} \int_{0}^{\tau}\left\langle N_{q} u^{(q)}, u^{(q)}\right\rangle_{\mathfrak{U}} d t, \quad z=C x,
$$

where $0 \leq k \leq p+1$. The operators $N_{q} \in \mathcal{L}(\mathfrak{U})$ for $q=0,1, \ldots, p+1$ are self-adjoint and positive definite, while $z_{d}=z_{d}(t, s)$ is an observation from some space of observations $\mathfrak{Z}$. Note that if $x \in H^{1}(\mathfrak{X})$ then $z \in H^{1}(\mathfrak{Z})$. By analogy with $H^{p+1}(\mathfrak{Y})$, define the space $H^{p+1}(\mathfrak{U})$, which is a Hilbert space because so is $\mathfrak{U}$. We distinguish a convex and closed subset $H_{a d}^{p+1}(\mathfrak{U})$ of the space $H^{p+1}(\mathfrak{U})$, called the set of admissible controls.

Definition 6. A vector function $v \in H_{a d}^{p+1}(\mathfrak{U})$ is called an optimal control of solutions to problem (5), (8) whenever

$$
J(v)=\min _{(x(u), u) \in \mathfrak{X} \times H_{a d}^{p+1}(\mathfrak{U})} J(u),
$$

where the pairs $(x(u), u) \in \mathfrak{X} \times H_{a d}^{p+1}(\mathfrak{U})$ satisfy (5), (8).

By Theorem 2, a unique solution $x \in H^{1}(\mathfrak{X})$ to problem $(5),(8)$ exists for all vectors $x_{j} \in \mathfrak{X}$ for $j=\overline{0, n}$, vector functions $f \in H^{p+1}(\mathfrak{Y}), u \in H^{p+1}(\mathfrak{U})$ and a function $a \in$ $C^{p+1}\left([0, T) ; \mathbb{R}_{+}\right)$separated from zero:

$$
x(t)=-\sum_{q=0}^{p} H^{q} M_{0}^{-1}(I-Q)\left(\frac{1}{a(t)} \frac{d}{d t}\right)^{k} \frac{f(t)+B u(t)}{a(t)}+
$$




$$
+\sum_{j=0}^{n}\left(X_{j}^{A(t)-A\left(\tau_{j}\right)} x_{\tau_{j}}-\int_{t}^{\tau_{j}} X_{j}^{A(t)-A(s)} L_{1 j}^{-1} Q_{j}(f(s)+B u(s)) d s\right)
$$

by analogy with [6]. Here $A(t)=\int_{0}^{t} a(\varsigma) d \varsigma$. We now fix $x_{j} \in \mathfrak{X}$ for $j=\overline{0, n}$ and $f \in$ $H^{p+1}(\mathfrak{Y})$ and consider $(11)$ as a mapping $D: u \rightarrow x(u)$.

Lemma 4. Given Hilbert spaces $\mathfrak{X}, \mathfrak{Y}$, and $\mathfrak{U}$, take an $(L, p)$-bounded operator $M$, with $p \in \mathbb{N}_{0}$, a function $a \in C^{p+1}\left(\overline{\mathbb{R}}_{+} ; \mathbb{R}_{+}\right)$separated from zero, and fix vectors $x_{j} \in \mathfrak{X}$ for $j=\overline{0, n}$ and $f \in H^{p+1}(\mathfrak{Y})$. Then the mapping $D: H^{p+1}(\mathfrak{U}) \rightarrow H^{1}(\mathfrak{X})$ defined by (11) is continuous.

Proof. Since $B \in \mathcal{L}\left(H^{p+1}(\mathfrak{U}) ; H^{p+1}(\mathfrak{Y})\right)$ and (11) is the solution to (8), this lemma holds by the properties of the operator group $X^{t}$ and the continuity of $a(t)$ for $t \in \overline{\mathbb{R}}_{+}$, by analogy with the proof of Theorem 2 .

Theorem 3. Take an $(L, p)$-bounded operator $M$ with $\left(p \in \mathbb{N}_{0}\right)$ and a function $a \in$ $C^{p+1}\left([0, \tau) ; \mathbb{R}_{+}\right)$separated from zero. Then for all vectors $x_{j} \in \mathfrak{X}$ for $j=\overline{0, n}, f \in$ $H^{p+1}(\mathfrak{Y})$, and $z_{d} \in \mathfrak{Z}$, there exists a unique solution $v \in H_{a d}^{p+1}(\mathfrak{U})$ to the optimal control problem (5), (8)-(10).

Proof. Using the mapping $D$ of Lemma 4, we see that the functional (9) becomes

$$
J(u)=\left\|C x(t ; u)-z_{d}\right\|_{H^{1}(\mathfrak{Z})}^{2}+[\eta, u],
$$

where $\eta^{(k)}(t)=N_{k} u^{(k)}$ for $k=0, \ldots, p+1$. Therefore,

$$
J(u)=\pi(u, u)-2 \theta(u)+\left\|z_{d}-C x(t ; 0)\right\|_{H^{1}(\mathfrak{Z})}^{2},
$$

where $\quad \pi(u, u)=\|C(x(t ; u)-x(t ; 0))\|_{H^{1}(\mathfrak{3})}^{2}+[\eta, u] \quad$ is a coercive continuous bilinear form on $H^{p+1}(\mathfrak{U})$, and

$$
\theta(u)=\left\langle z_{d}-C x(t ; 0), C(x(t ; u)-x(t ; 0))\right\rangle_{H^{1}(\mathfrak{Z})}
$$

is a continuous linear form on $H^{p+1}(\mathfrak{U})$. Thus, the theorem is valid by analogy with [6].

\section{References}

1. Favini A., Yagi A. Degenerate Differential Equations in Banach Spaces. New York, Basel, Hong Kong, Marcel Dekker, Inc, 1999. 236 p.

2. Demidenko G.V., Uspenskii S.V. Partial Differential Equations and Systems not Solvable with Respect to the Highest-Order Derivative. New York, Basel, Hong Kong, Marcel Dekker, Inc, 2003. 239 p.

3. Sviridyuk G.A., Fedorov V.E. Linear Sobolev Type Equations and Degenerate Semigroups of Operators. Utrecht, Boston, Köln, VSP, 2003. 216 p. DOI: $10.1515 / 9783110915501$ 
4. Al'shin A.B., Korpusov M.O., Sveshnikov A.G. Blow-up in Nonlinear Sobolev Type Equations. Berlin, de Gruyter, 2011. 648 p.

5. Zagrebina S.A. The Multipoint Initial-Finish Problem for the Stochastic BarenblattZheltov-Kochina Model. Bulletin of the South Ural State University. Series: Computer Technologies, Automatic Control, Radio Electronics, 2013, vol. 13, no. 3, pp. 5-11. (in Russian)

6. Sagadeeva M.A., Badoyan A.D. The Optimal Control over Solutions of Special Form of Nonstacionary Sobolev Type Equations in Relatively Spectral Case. Vestnik Magnitogorskogo gosudarstvennogo universiteta. Matematika [Bulletin of Magnitogorsk State University. Mathematics], 2013, no. 15, pp. 68-80. (in Russian)

7. Sagadeeva M.A., Badoyan A.D. The Problem of Optimal Control over Solutions of the Nonstationary Barenblatt-Zheltov-Kochina Model. Bulletin of the South Ural State University. Series: Computer Technologies, Automatic Control, Radio Electronics, 2014, vol. 14, no. 2, pp. 5-11.

8. Zagrebina S., Sagadeeva M. The Generalized Splitting Theorem for Linear Sobolev type Equations in Relatively Radial Case. Izvestiya Irkutskogo gosudarstvennogo universiteta. Seriya: Matematika [The Bulletin of Irkutsk State University. Series: Mathematics], 2013, vol. 7, pp. 19-33.

9. Keller A.V. Relatively Spectral Theorem. Vestnik Chelyabinskogo gosudarstvennogo universiteta. Seriya Matematika. Mekhanika [Bulletin of the Chelyabinsk State University. Series of Mathematic and Mechanic], 1996, no. 1 (3), pp. 62-66. (in Russian)

\title{
ОПТИМАЛЬНОЕ УПРАВЛЕНИЕ РЕШЕНИЯМИ МНОГОТОЧЕЧНОЙ НАЧАЛЬНО-КОНЕЧНОЙ ЗАДАЧИ ДЛЯ НЕСТАЦИОНАРНЫХ ОТНОСИТЕЛЬНО ОГРАНИЧЕННЫХ УРАВНЕНИЙ СОБОЛЕВСКОГО ТИПА
}

\author{
М.А. Сагадеева, А.Д. Бадоян
}

\begin{abstract}
В статье рассматривается оптимальное управление решениями начально-конечной задачи для операторно-дифференциального уравнения, неразрешенного относительно производной. При этом в уравнении один из операторов умножен на скалярную функцию переменной $t$, и свойства операторов таковы, что стационарное уравнение обладает аналитической разрешающей группой. В статье строится сильное решение начально-конечной задачи для нестационарного уравнения соболевского типа в случае относительной ограниченности. Используя построенное решение, доказывается существование единственного оптимального управления решениями указанной задачи. Статья кроме введения и списка литературы содержит три части. В первой из них приводятся необходимые сведения теории относительно $p$-ограниченных операторов, во второй - строится сильное решение многоточечной начально-конечной задачи для нестационароного уравнения соболевского типа. Наконец, в третьей части доказывается существование и единственность оптимального управления решениями начальноконечной задачи для нестационарного уравнения соболевского типа.
\end{abstract}

Ключевые слова: оптимальное управление; многоточечная начально-конечная задача; уравнения соболевского типа; относительно ограниченный оператор. 


\section{Литература}

1. Favini, A. Degenerate Differential Equations in Banach Spaces / A. Favini, A. Yagi. - N.Y.; Basel; Hong Kong: Marcel Dekker, Inc, 1999. - 236 pp.

2. Demidenko, G.V. Partial Differential Equations and Systems not Solvable with Respect to the Highest-Order Derivative / G.V. Demidenko, S.V. Uspenskii. - N.Y; Basel; Hong Kong: Marcel Dekker Inc, 2003. - 239 p.

3. Sviridyuk, G.A. Linear Sobolev Type Equations and Degenerate Semigroups of Operators / G.A. Sviridyuk, V.E. Fedorov. - Utrecht; Boston; Köln: VSP, 2003. -216 p.

4. Al'shin, A.B. Blow-up in Nonlinear Sobolev Type Equations / A.B. Al'shin, M.O. Korpusov, A.G. Sveshnikov. - Berlin: de Gruyter, 2011. - 648 p.

5. Загребина, С.А. Многоточечная начально-конечная задача для стохастической модели Баренблатта-Желтова-Кочиной / С.А. Загребина // Вестник ЮУрГУ. Серия: Компьютерные технологии, управление, радиоэлектроника. - 2013. - T. 13, № 4. - C. 103-111.

6. Сагадеева, М.А. Оптимальное управление решениями нестационарных уравнений соболевского типа специального вида в относительно секториальном случае / М.А. Сагадеева, А.Д. Бадоян // Вестник Магнитогорского государственного университета. Математика. - 2013. - Вып. 15. - С. 68-80.

7. Sagadeeva, M.A. The Problem of Optimal Control over Solutions of the Nonstationary Barenblatt-Zheltov-Kochina Model / M.A. Sagadeeva, A.D. Badoyan // Вестник ЮУрГУ. Серия: Компьютерные технологии, управление, радиоэлектроника. 2014. - T. 14, № 2. - C. 5-11.

8. Zagrebina, S. The Generalized Splitting Theorem for Linear Sobolev type Equations in Relatively Radial Case / S. Zagrebina, M. Sagadeeva // Известия Иркутского государственного университета. Серия: Математика. - 2014. - Т. 7. - С. 19-33.

9. Келлер, А.В. Относительно спектральная теорема / А.В. Келлер // Вестник Челябинского государственного университета. Серия Математика. Механика. 1996. - № 1 (3). - C. 62-66.

Минзиля Алмасовна Сагадеева, кандидат физико-математических наук, доцент, кафедра «Уравнения математической физики», Южно-Уральский государственный университет (г. Челябинск, Российская Федерация), sam79@74.ru.

Ани Давидовна Бадоян, аспирант, кафедра «Уравнения математической физики», Южно-Уральский государственный университет (г. Челябинск, Российская Федерация), badoyanani@mail.ru.

Поступила в редакиию 15 мая 2014 г. 